\title{
Itinerarios a través del paisaje de la producción de azúcar
}

Antonio Manuel Díaz Muñoz | arquitecto

URL de la contribución <www.iaph.es/revistaph/index.php/revistaph/article/view/3587>

\section{RESUMEN}

En el año 2006 tendría lugar la última campaña de producción de azúcar en la Azucarera N. ${ }^{a}$ S. ${ }^{a}$ del Rosario de Salobreña, última fábrica de azúcar de caña de Europa, quedando atrás la historia viva de un sector productivo que había marcado el paisaje de la costa andaluza desde tiempos de alÁndalus.

La reactivación del sector azucarero y la expansión industrial producida a mediados del siglo XIX promoverían importantes cambios en los sistemas agrario y productivo tradicionales provocando transformaciones económicas, sociales y culturales, que redefinirían y enmarcarían el paisaje de la producción de azúcar. Un paisaje complejo caracterizado por diversos componentes físico-naturales, culturales y sensitivos.

Las consecuencias negativas sufridas por la arquitectura industrial tras el cese de la actividad azucarera proporcionan un escenario hacia donde dirigir lecturas e itinerarios sobre el paisaje de la producción de azúcar. Surgen tres itinerarios a través de la arquitectura desaparecida, de la arquitectura prácticamente desaparecida y la arquitectura abandonada.

\section{Palabras clave}

Arquitectura | Azúcar | Azucareras | Conservación (Patrimonio) | Costa de Granada | Cultivo industrial | Itinerario | Patrimonio industrial | Rehabilitación arquitectónica | 


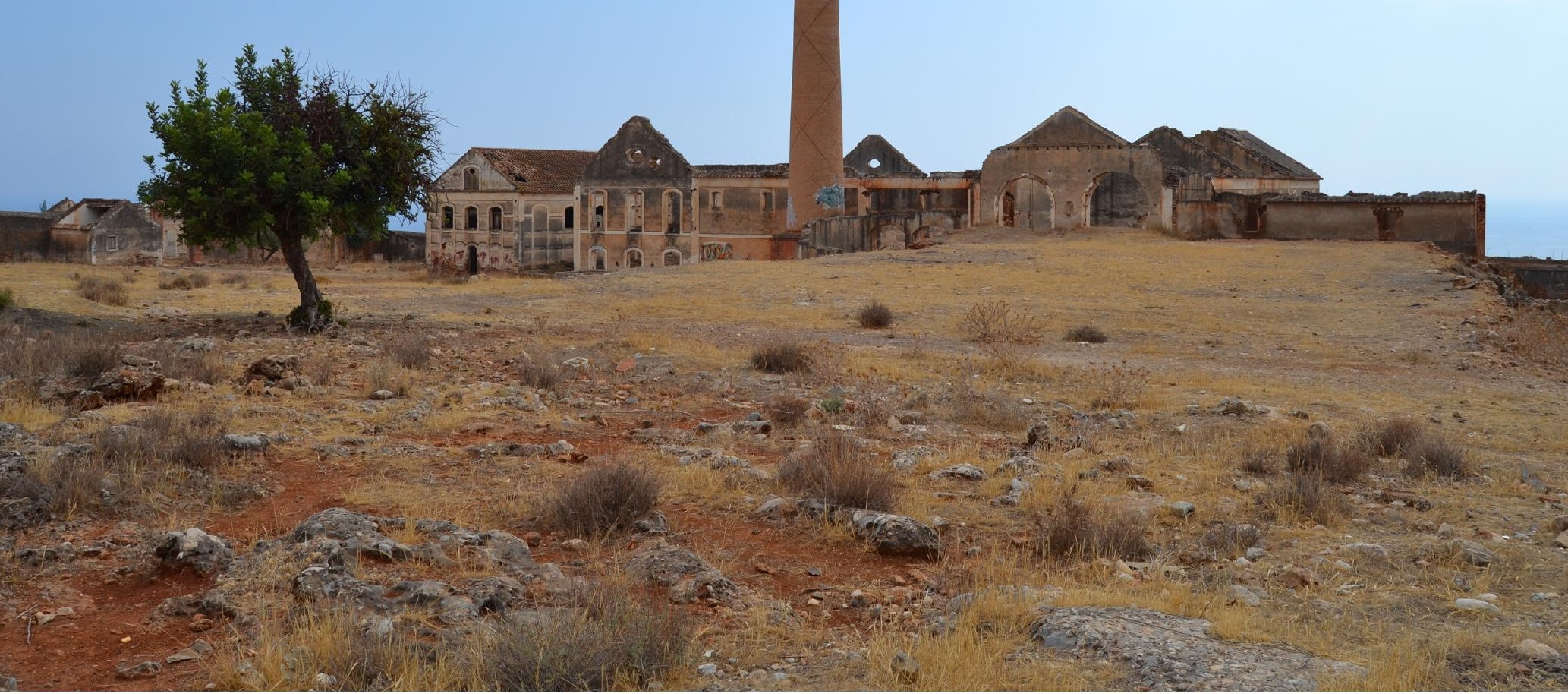

Fábrica de las Mercedes. Azucarera-alcoholera de San Joaquín. Marzo, 2014 | foto Antonio M. Díaz Muñoz 


\section{PAISAJE DE LA PRODUCCIÓN DE AZÚCAR}

En el año 2006 tendría lugar la última campaña de producción de azúcar en la Azucarera N. ${ }^{a}$ S. ${ }^{a}$ del Rosario de Salobreña, última fábrica de azúcar de caña de Europa, quedando atrás la historia viva de un sector productivo que había marcado el paisaje de la costa andaluza desde tiempos de al-Ándalus (MALPICA CUELLO, 1991: 125-129; GARCÍA SÁNCHEZ, 1995: 47-59).

La reactivación del sector azucarero y la expansión industrial producida a mediados del siglo XIX promovieron importantes cambios en los sistemas agrario y productivo tradicionales provocando transformaciones económicas, sociales y culturales, que redefinirían y enmarcarían el paisaje de la producción de azúcar.

La emergente expansión industrial demandaría mayor cantidad de materia prima, provocando que los cultivos de caña de azúcar se extendieran colmando terrenos de regadío, de baja calidad, incultos e incluso marginales. Daría lugar igualmente a un crecimiento de propietarios y a nuevos modelos de explotación agrícolas basados en la autogestión de la pequeña propiedad y en la fragmentación de las grandes para el arrendamiento o la gestión por jornaleros estacionales.

Siendo un proceso productivo que exigía gran intensidad de trabajo en periodos relativamente cortos, era necesaria gran cantidad de mano de obra temporal adaptada a la estacionalidad de las actividades agrarias y la transformación industrial. Los requerimientos tecnológicos de los nuevos modos de producción necesitarían de una nueva arquitectura de gran magnitud, robustez, esbeltez, funcional, etc., que ofreciese grandes volúmenes interiores capaces de albergar las distintas fases de la producción: como serían las naves de molinos, naves de fabricación, salas de calderas, almacenes de azúcar, etc., ubicadas de tal manera que mantenían la proximidad con el entorno agrario requerida en toda industria agroalimentaria. Eran necesarios también unos espacios de menor envergadura que cubrían funciones menores de la industria como los aperos agrícolas, talleres, laboratorios, oficinas, etc., y, en ciertos casos, espacios complementarios como viviendas, escuelas o capillas, que terminasen de dar equipamiento al conjunto de la fábrica. Igualmente preciso era la creación y mejora de infraestructuras que favoreciesen y garantizasen el abastecimiento de ciertas materias primas y la posterior exportación del azúcar y los subproductos derivados de su producción.

La producción de azúcar daría lugar a un paisaje complejo, formado por diversos componentes. Su componente físico-natural estaría caracterizado por un territorio fragmentado, colmatado por cultivos de caña extendidos por las vegas del litoral y sus costas componiendo un mar de cañas; una arqui- 
tectura surgida como centro neurálgico entre el entorno agrario e industrial, que modela los espacios e instalaciones, que demanda de infraestructuras y se impone como icono del lugar.

De igual modo tiene un componente cultural, donde se refleja la estructura socioeconómica del momento, la cultura del trabajo, las relaciones entre fabricantes y agricultores, propietarios y colonos o jornaleros, patronos y obreros, además de las relaciones familiares, los modos de vida, las costumbres, tradiciones, etc.

Dentro de ellos, quizás el elemento menos reconocido como integrante del paisaje de la producción de azúcar sea el componente sensitivo generado por una industria como la azucarera, donde la percepción y los sentidos juegan un papel fundamental a la hora de caracterizar el paisaje. La percepción de los colores, texturas, olores, sabores, incluso los sonidos o los ruidos durante el proceso productivo son aspectos esenciales que matizan la percepción del paisaje.

\section{ITINERARIOS A TRAVÉS DEL PAISAJE DE LA PRODUCCIÓN DE AZÚCAR}

El progresivo abandono del cultivo de cañas, el cese de la actividad industrial y el cierre de las fábricas avenido durante el siglo XX acarrearían consecuencias negativas a la arquitectura representativa del paisaje de la producción de azúcar. Parte de ella sería transformada y reutilizada por otras industrias alargando su vida útil; otra parte sería demolida total o parcialmente; mientras que otra parte sería abandonada, a la espera de nuevas circunstancias.

Cada uno de estos escenarios permite trazar distintos itinerarios que revelan diferentes lecturas de la realidad de un mismo paisaje: una lectura a través de la arquitectura ya desaparecida; otra a través de resto de elementos en pie; y por último, la de una arquitectura que continúa abandonada.

\section{Itinerario A: arquitectura desaparecida}

Se trata de un itinerario complejo, cuyo recorrido se realiza empleando la información conseguida de imágenes y documentos históricos donde aún queda plasmada parte de la impronta que dejaron en el paisaje de la producción de azúcar.

En su recorrido se empleará como apoyo un cuadro rememorativo donde reflejar la totalidad de fábricas industriales de azúcar desaparecidas en la costa de Andalucía, así como referencias gráficas de algunas de ellas que permitan dar una cierta idea de su aporte paisajístico.

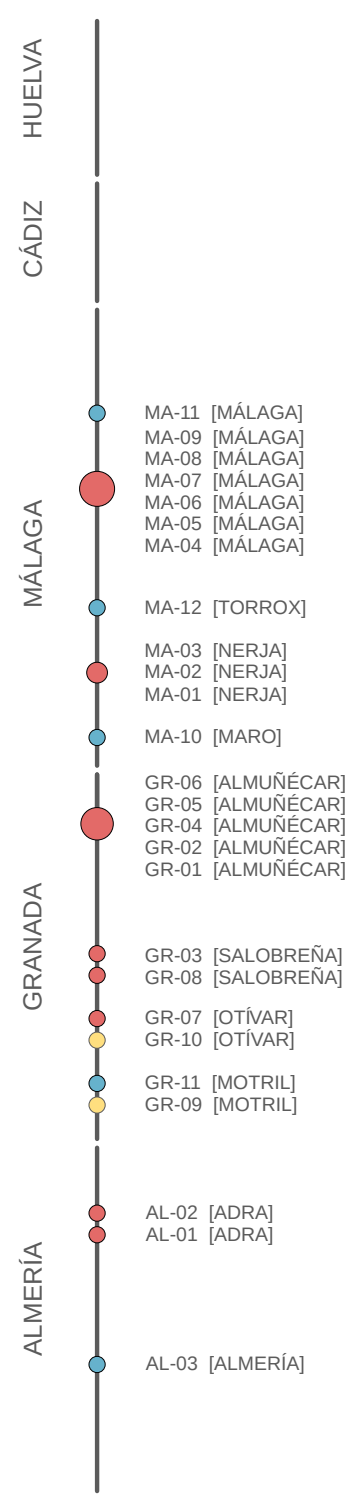

arquitecturas desaparecidas arquitecturas prácticamente desaparecidas arquitecturas abandonadas 


\begin{tabular}{|c|c|c|c|c|c|}
\hline \multicolumn{6}{|c|}{ ITINERARIO A: Arquitectura desaparecida } \\
\hline Id & Nombre de la fábrica & Primeros propietarios & Localidad & Año de apertura & Año de cierre \\
\hline AL- 01 & $\begin{array}{l}\text { Fca. Ntra. Sra. de la Aurora o } \\
\text { Fca. de Azúcar la Alquería }\end{array}$ & $\begin{array}{l}\text { Soc. Anónima Fca. Ntra. Sra. } \\
\text { de la Aurora (Antonio Martín } \\
\text { Toro y Cristóbal Ochoa y López) }\end{array}$ & Adra & 1884 & 1904 \\
\hline AL- 02 & $\begin{array}{l}\text { Fca. Castell e hijos o } \\
\text { La Gloria/Ingenio de } \\
\text { San Nicolás }\end{array}$ & $\begin{array}{l}\text { Sociedad Castell e Hijo / } \\
\text { Sociedad Hijos de M. A. } \\
\text { Heredia }\end{array}$ & Adra & 1870 & 1942 \\
\hline GR-01 & La Purísima Concepción & - & Almuñécar & 1906 & 1912 \\
\hline GR-02 & $\begin{array}{l}\text { Fca. Ntra. Sra. del Pilar o } \\
\text { La Peninsular }\end{array}$ & $\begin{array}{l}\text { Sociedad Azucarera } \\
\text { Peninsular }\end{array}$ & Almuñécar & 1846 & - \\
\hline GR-03 & $\begin{array}{l}\text { Fca. Ntra. Sra. del Carmen } \\
\text { o Azucarera Ntra. Sra. } \\
\text { de la Encarnación }\end{array}$ & $\begin{array}{l}\text { Sociedad Felipe Micó/ } \\
\text { Torrent y Cia. } \\
\text { Rafael Márquez y } \\
\text { Encarnación Márquez/Sociedad } \\
\text { Hijos de Rafael Márquez }\end{array}$ & Almuñécar & $\begin{array}{l}1866 \\
1890\end{array}$ & 1950 \\
\hline GR-04 & Fca. Ntra. Sra. de la Victoria & - & Almuñécar & 1907 & 1919 \\
\hline GR-05 & La Redención & - & Almuñécar & - & 1901 \\
\hline GR-06 & Azucarera Santa Teresa & - & Almuñécar & - & 1956 \\
\hline GR-07 & Fca. Ntra. Sra. del Carmen & - & Otívar & 1911 & 1952 \\
\hline GR-08 & Fca. Ntra. Sra. del Pilar & Sociedad Azucarera Peninsular & Salobreña & 1874 & 1912 \\
\hline MA-01 & Fca. Ntra. Sra. de las Angustias & $\begin{array}{l}\text { Sociedad Azucarera Navas, } \\
\text { Padre y Hermana }\end{array}$ & Nerja & 1864 & - \\
\hline MA-02 & Fca. de Mieles El Progreso & Francisco Cantero & Nerja & 1873 & 1920 \\
\hline MA-03 & $\begin{array}{l}\text { Fca. de los Cangrejos. } \\
\text { La Independencia. San Clemente }\end{array}$ & $\begin{array}{l}\text { Sociedad Mercantil } \\
\text { comandataria Rico, } \\
\text { Ferrándiz, Retamero y Cía. }\end{array}$ & Nerja & 1882 & 1886 \\
\hline MA-04 & $\begin{array}{l}\text { Fca. de Azúcar de Caña y } \\
\text { Alcoholes La Hispania }\end{array}$ & Azucarera Ibérica S.A. & Málaga & 1930 & 1994 \\
\hline MA-05 & Fca. Ntra. Sra. de la Concepción & José Smith & Málaga & 1862 & 1939 \\
\hline MA-06 & $\begin{array}{l}\text { Ingenio Ordóñez o Azucarera } \\
\text { del Guadalhorce }\end{array}$ & Martín Heredia y Hermanos & Málaga & 1885 & 1908 \\
\hline MA-07 & Azucarera La Malagueta & $\begin{array}{l}\text { Sociedad Martín Heredia } \\
\text { e Hijos }\end{array}$ & Málaga & 1858 & 1906 \\
\hline MA-08 & Azucarera San Guillermo & $\begin{array}{l}\text { Sociedad anónima } \\
\text { Fca. Azucarera San Guillermo }\end{array}$ & Málaga & $1876-1884$ & 1899 \\
\hline MA-09 & Azucarera la Santísima Trinidad & $\begin{array}{l}\text { Hermanos José y Sebastián } \\
\text { Briales y Domínguez y } \\
\text { Simón Castell y Sáenz }\end{array}$ & Churriana & 1902 & 1903-1942 \\
\hline
\end{tabular}



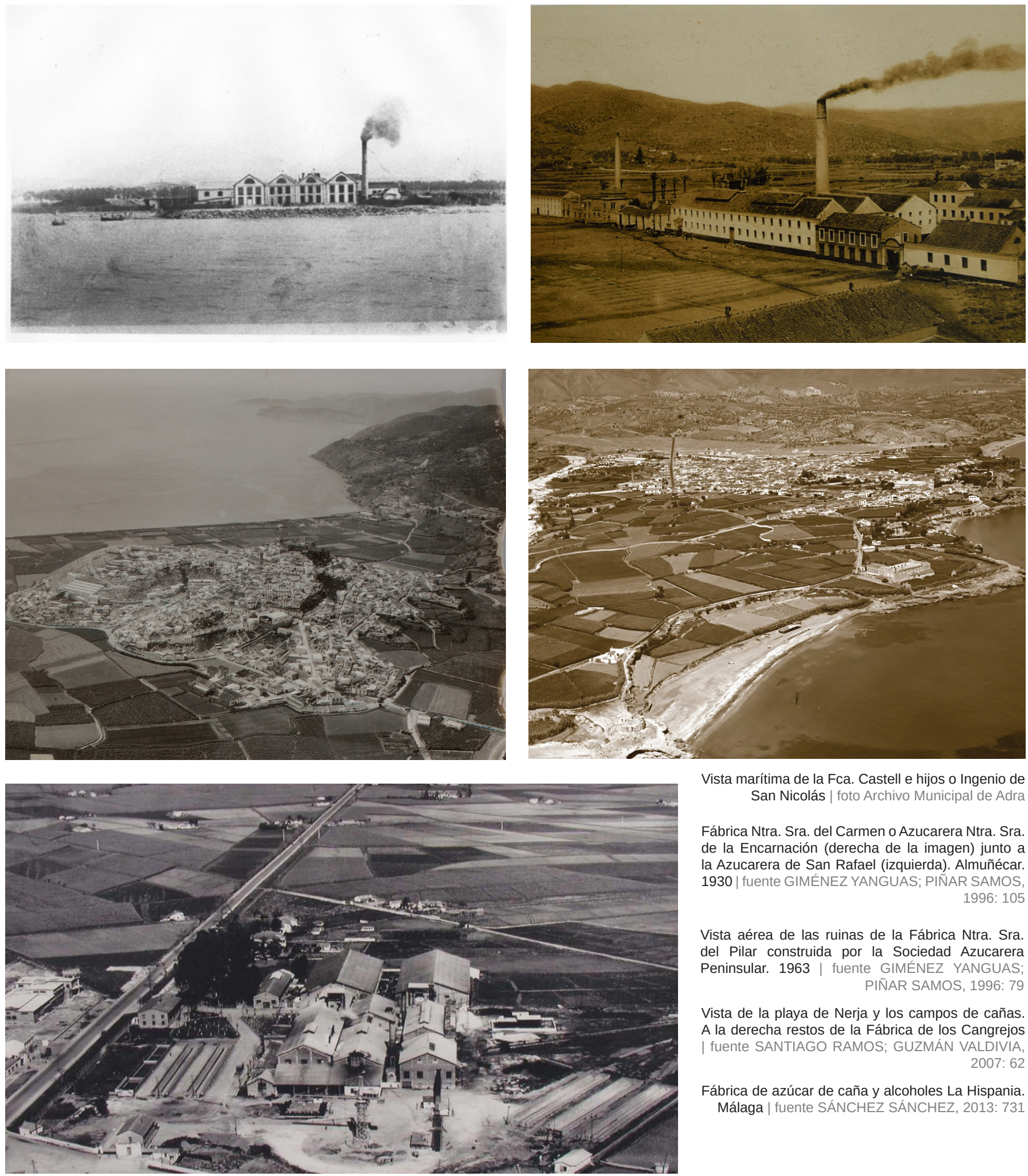

Vista marítima de la Fca. Castell e hijos o Ingenio de San Nicolás | foto Archivo Municipal de Adra

Fábrica Ntra. Sra. del Carmen o Azucarera Ntra. Sra. de la Encarnación (derecha de la imagen) junto a la Azucarera de San Rafael (izquierda). Almuñécar. 1930 | fuente GIMÉNEZ YANGUAS; PIÑAR SAMOS,

$$
\text { 1996: } 105
$$

Vista aérea de las ruinas de la Fábrica Ntra. Sra. del Pilar construida por la Sociedad Azucarera Peninsular. 1963 | fuente GIMÉNEZ YANGUAS; PIÑAR SAMOS, 1996: 79

Vista de la playa de Nerja y los campos de cañas. A la derecha restos de la Fábrica de los Cangrejos | fuente SANTIAGO RAMOS; GUZMÁN VALDIVIA, 2007: 62

Fábrica de azúcar de caña y alcoholes La Hispania. Málaga | fuente SÁNCHEZ SÁNCHEZ, 2013: 731 
Restos de la Fábrica San José. La Melcochera. Otívar. 2012 | foto Antonio M. Díaz Muñoz

Chimenea de la Azucarera de San Fernando. La Motrileña. Motril. 2012 | foto Antonio M. Díaz Muñoz

Puerta principal de la Fábrica Ntra. Sra. de Montserrat, desmontada y trasladada a un parque próximo en la barriada de El Puche, Almería. 2010 foto ANE (www.wikipedia.org)
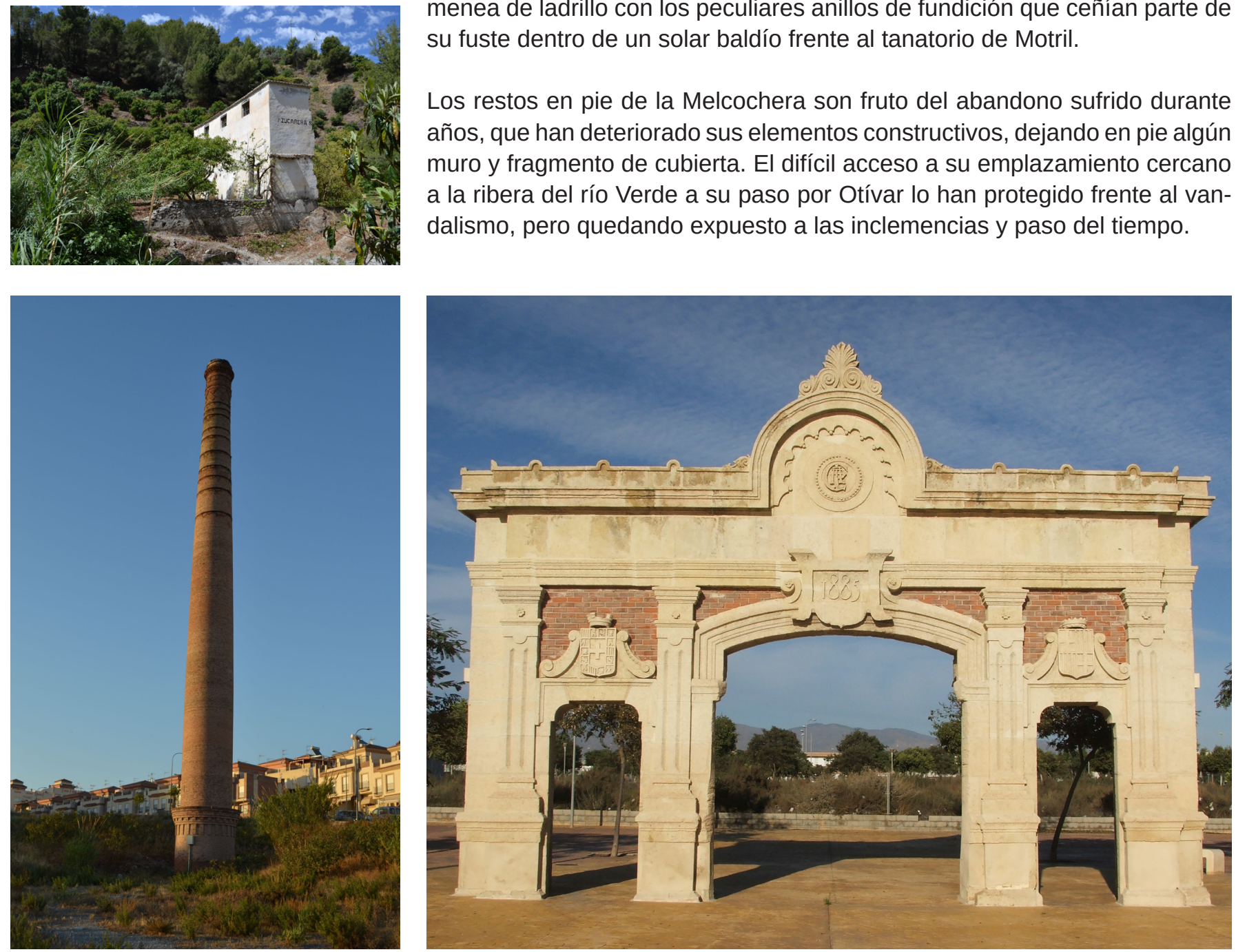

Itinerario B: arquitectura prácticamente desaparecida

Un Itinerario a través de la arquitectura prácticamente desaparecida pone de manifiesto diferentes casuísticas que llevarían a conservar parcialmente algunos de los componentes de la arquitectura del azúcar.

La puerta principal en sillería, único elemento en pie de la Fábrica Ntra. Sra. de Montserrat, fue desmontada y vuelta a montar en un parque cercano a la situación de la finca donde se ubicaba. Actualmente descontextualizada dentro de un paisaje urbano en la barriada de El Puche, se establece como icono de la industria azucarera en Almería.

Tras la demolición en el año 1996 de la Azucarera de San Fernando, o La Motrileña como más frecuentemente se conocía, se conserva tan solo la chimenea de ladrillo con los peculiares anillos de fundición que ceñían parte de su fuste dentro de un solar baldío frente al tanatorio de Motril.

Los restos en pie de la Melcochera son fruto del abandono sufrido durante años, que han deteriorado sus elementos constructivos, dejando en pie algún muro y fragmento de cubierta. El difícil acceso a su emplazamiento cercano a la ribera del río Verde a su paso por Otívar lo han protegido frente al vandalismo, pero quedando expuesto a las inclemencias y paso del tiempo. 


\begin{tabular}{|c|c|c|c|c|c|}
\hline Id & Nombre de la fábrica & Primeros propietarios & Localidad & Año de apertura & Año de cierre \\
\hline AL- 03 & Fca. Ntra. Sra. de Montserrat & María Becerra Góngora & Almería & 1870 & 1942 \\
\hline GR-09 & $\begin{array}{l}\text { Fca. Sta. Margarita- } \\
\text { Las tres hermanas. Azucarera } \\
\text { de San Fernando. La Motrileña }\end{array}$ & $\begin{array}{l}\text { Bermúdez de Castro/ } \\
\text { Duquesa de Santoña }\end{array}$ & Motril & 1914 & 1977 \\
\hline GR-10 & Fca. San José. La Melcochera & - & Otívar & 1906 & 1921 \\
\hline
\end{tabular}

\section{Itinerario C: arquitectura abandonada}

Un Itinerario por la arquitectura abandonada permite generar una idea aproximada de cómo era la arquitectura de la industria azucarera (su escala, dimensión, magnitud, etc.) en primera persona, permitiendo llegar a comprender cómo, cuáles y de qué tipo eran las relaciones que llegaron a establecerse con el paisaje de la producción de azúcar. Aporta una visión propia que ayuda a tomar conciencia del estado de abandono en el que se encuentra, de las relaciones que establece actualmente con el paisaje, y de la importancia que supone su puesta en valor, su protección, su conservación y, por qué no, su rehabilitación.

\section{Santa Isabel (Motril)}

La fábrica comenzaría siendo propiedad de Isabel Gisbert López-Tornel, I Condesa de Torre-Isabel, constituyéndose como Sociedad Azucarera Santa Isabel en el año 1902. La complicada situación que experimentaría en los años 20 la llevaría a buscar nuevo capital entre los señores de Motril constituyendo una nueva sociedad. A pesar del nuevo aporte de capital, terminaría desapareciendo al finalizar la Guerra Civil, sirviendo su maquinaria para la constitución de una azucarera en Almuñécar.

Tras su cierre, la edificación se adaptaría y acogería una subestación eléctrica, actualmente en desuso y en estado de precariedad. El desplome de parte de su cubierta y cerramientos en el cuerpo principal acrecientan el deterioro exterior e interior. Junto a ella se conservan varias edificaciones, almacenes, aperos, viviendas, etc., en un estado similar de conservación rodeado de plantaciones de aguacates y chirimoyos en el camino de Minasierra, visible desde la N-340 hacia Motril.

\section{San Joaquín (Maro)}

La familia Larios sería la última propietaria de la Azucarera y Alcoholera de San Joaquín cerrando sus instalaciones en el año 1950, transcurridos 71 años de su fundación a manos de Joaquín Pérez del Pulgar en el año 1879. A lo largo de su historia, la fábrica pasaría por diferentes propietarios conservando en todo momento la actividad industrial. 

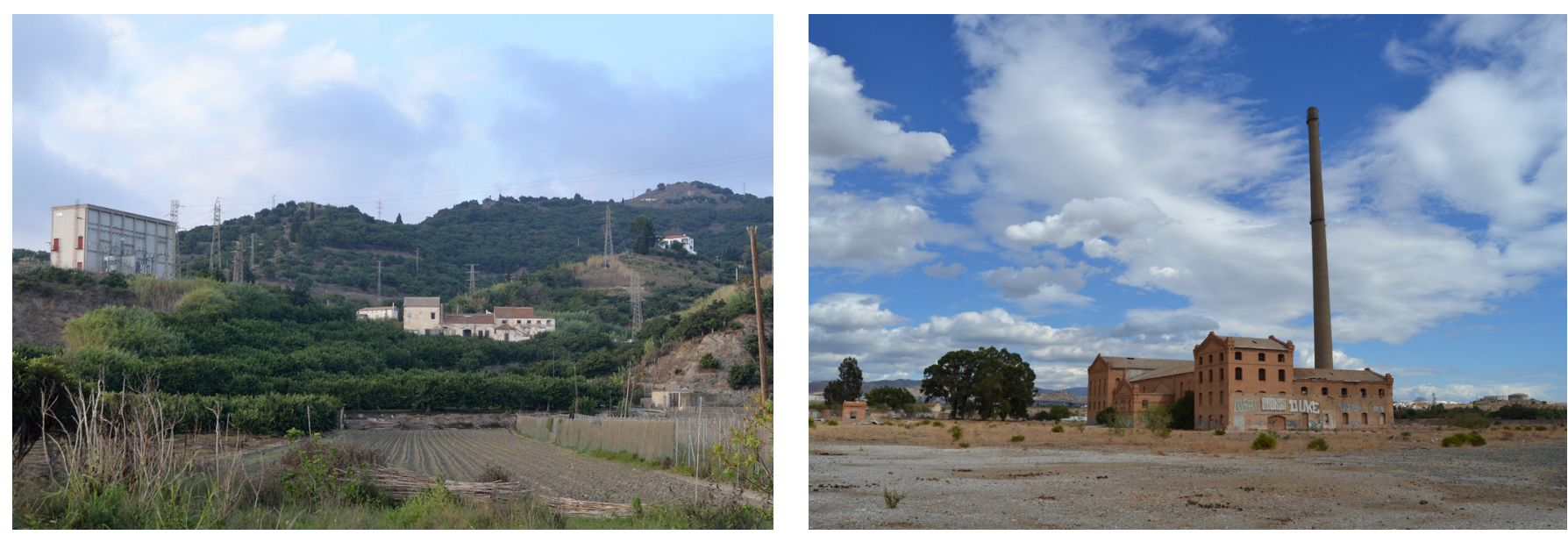

Fábrica Santa Isabel. Motril. 2014 | foto Antonio M. Díaz Muñoz

El Tarajal. Azucarera N. ${ }^{\text {a }}$ S. ${ }^{\text {a }}$ de la Victoria. 2014. Málaga | foto Antonio M. Díaz Muñoz
El conjunto arquitectónico contaría con una fábrica de azúcar, una destilería de alcohol, una casa de recreo con zona ajardinada, veinticuatro casas para colonos y operarios, varios almacenes, destacando sobre el conjunto el diseño de la chimenea y el estanque en la entrada principal de la fábrica.

Actualmente a pesar de conservar restos de todo el conjunto, su abandono ha acrecentado el deterioro, conduciendo al estado de ruina parte de la edificación. El cuerpo central de la fábrica, la destilería, un conjunto de viviendas y una pequeña dependencia en el acceso lateral son los elementos arquitectónicos mejor conservados. La pérdida de las cubiertas en la mayor parte de la edificación está acelerando el deterioro y destrucción de la estructura portante y los cerramientos.

San Joaquín continúa formando parte de un paisaje agrícola configurado en parcelas y campos de cultivo similar a los tiempos de la producción de azúcar, que se extienden entre la sierra de la Almijara y el mar.

\section{El Tarajal}

La Azucarera Nuestra Señora de la Victoria, más conocida como Azucarera de El Tarajal, cesaría su actividad como productora de azúcar en el año 1939, empleándose sus instalaciones en la industria del corcho como Corchera Ibérica hacia 1946. Tres décadas después, las instalaciones se abandonarían tras ser utilizadas como espacio de almacenamiento. En la actualidad se presenta como un conjunto arquitectónico abandonado, aprovechado como lugar de pastoreo para caballo, potros y mulas.

El conjunto industrial conserva varios de sus elementos arquitectónicos aunque en estado de precariedad. Cuenta con un edificio principal, organizado en diferentes naves, y un cuerpo anexo donde se localizan las oficinas; una 
chimenea, un depósito de agua y un edificio de control; el resto de la edificación compuesta por varios edificios de control de acceso y recepción, varios almacenes, una casa de dirección, una casa para oficiales y unas viviendas para obreros fueron demolidas en el mes de mayo de 2014.

Presenta daños generalizados en cubiertas, llegando al desplome parcial o total de las mismas en ciertos casos; la estructura portante, muros de carga de fábrica de ladrillo en su mayoría, presenta daños leves pero generalizados, con ciertas lesiones de gravedad en zonas puntuales; las carpinterías prácticamente han desaparecido, al igual que los acabados, pavimentos hidráulicos o alicatados cerámicos, o se encuentran prácticamente destruidos consecuencia del vandalismo.

Actualmente se encuentra inmersa en un paisaje periurbano caracterizado por nuevas infraestructuras de comunicación, circunvalaciones, polígonos industriales, edificaciones de viejos cortijos y huertas de cítricos. Sus elementos arquitectónicos destacan sobre un escenario contemporáneo que parece nada tiene que ver con el paisaje de la producción de azúcar.

\section{Ingenio de San Rafael (Torrox)}

El origen de esta fábrica azucarera data del siglo XVI cuando la familia morisca de Los Melilla construye el Ingenio Bajo. En torno al año 1847 pasaría a manos de Javier León Bendicho y Quilty que promovería su rehabilitación dándole el nombre de Ingenio de San Rafael. En 1854 la propiedad es adquirida por Martín Larios Herrero transformándola en una de las fábricas de la Sociedad Azucarera Larios hasta el cese de actividad en el año 1945.

El emplazamiento del Ingenio en la ladera oeste del río Torrox favorecía una distribución estratigráfica de los elementos arquitectónicos en distintos planos. Presentaba por tanto una planta compleja donde los distintos componentes se distribuían en torno a un gran patio central. La fábrica contaba con un cuerpo central de fábrica compuesto por un conjunto de edificios de considerables dimensiones, varias salas de calderas, naves de almacenamiento, oficinas, viviendas para ingenieros, obreros y guardeses, cuartos de aperos, establos y una chimenea.

Presenta un abandono y deterioro generalizado, caracterizado por el desplome de cubiertas, forjados y ciertos muros interiores. La vegetación y la climatología acrecientan los daños en los elementos mejor conservados, como son el caso de las viviendas de ingenieros y ciertas partes del cuerpo de fábrica.

Su ubicación en el territorio le permite conservar una relación estrecha con el paisaje hacia el río, aun hoy convertido en terrazas cultivables. 


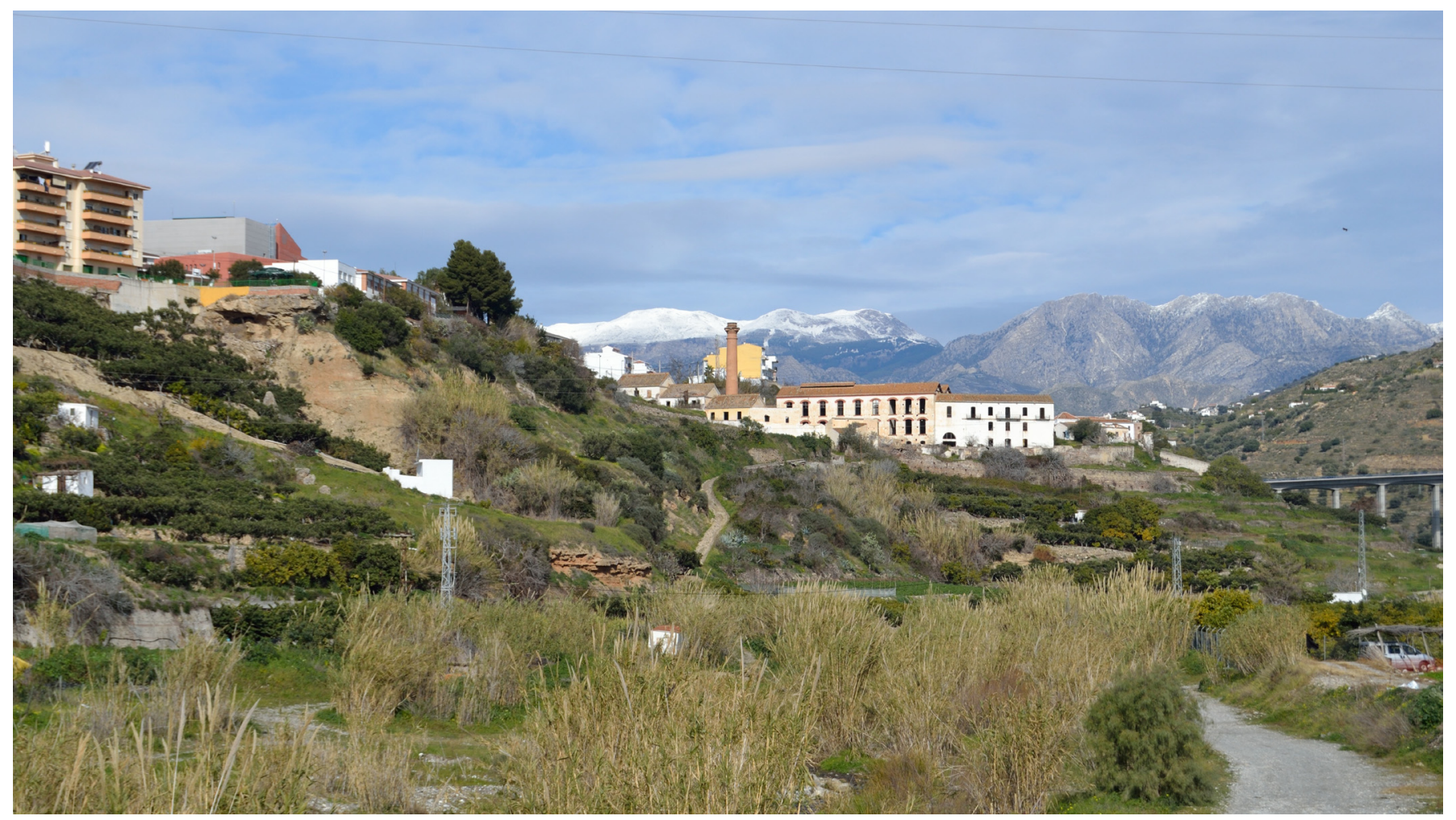

Ingenio de San Rafael. Ingenio Bajo. 2015. Torrox | foto Antonio M. Díaz Muñoz

\section{Más información:}

$>$ mapa de itinerarios
Complementariamente a los tres itinerarios trazados quedaría pendiente de resolución un cuarto recorrido donde poner en relieve la arquitectura industrial azucarera que ha sido de algún modo objeto de rehabilitación, ya fuese en su totalidad o en alguno de sus elementos arquitectónicos. Ciertas fábricas integrantes de ese futuro itinerario podrían ser Ntra. Sra. de la Almudena (Motril), Fábrica del Ángel (San Pedro de Alcántara) o la Fábrica Ntra. Sra. del Pilar (Motril) inscrita en el Catálogo General del Patrimonio Histórico Andaluz. 


\section{BIBLIOGRAFÍA}

- AA. VV. (1998) El Azúcar de la Costa. En Historia económica de Granada. Granada: Cámara de Comercio, Industria y Navegación, 1998, pp. 191-214

- ALBA DORADO, M. I. (2010) Paisajes de la memoria. Hacia una definición del paisaje industrial como paisaje cultural. En Actas del $V$ Congreso Conservación del Patrimonio Industrial y de la Obra Pública en España. El Ferrol: CICEES, 2010, pp. 447-452

- BOISSIER, CH. E. (1995) Viaje botánico al sur de España durante el año 1837. Granada: Caja de Ahorros de Granada, 1995

- DíAZ MUÑOZ, A. M. (2013) Tres Traslados. Patrimonio Industrial Azucarero en Andalucía. En Actas del VI Congreso Conservación del Patrimonio Industrial y de la Obra Pública en España. El patrimonio industrial en el contexto histórico del franquismo (1939-1975): territorios, arquitecturas, obras públicas, empresas, sindicatos y vida obrera. Documento inédito

- GARCíA SÁNCHEZ, E. (1995) Caña de azúcar y cultivos asociados en Al-Ándalus. En Paisajes del azúcar: Actas del Quinto Seminario Internacional sobre la caña de azúcar. Granada: Diputación Provincial, 1995, pp. 41-68

- GIMÉNEZ YANGUAS, M.; PIÑAR SAMOS, J. (1996) Motril y el azúcar: del paisaje industrial al patrimonio tecnológico 1845-1995. Motril (Granada): Asukaria Mediterránea, 1996

- GIMÉNEZ YANGUAS, M.; PIÑAR SAMOS, J. (2009) La arquitectura del azúcar en la provincia de Granada. En ÁlVAREZ ARECES, M. Á. (ed.) Patrimonio industrial agroalimentario: testimonios cotidianos de diálogo intercultural. Gijón: Incuna, 2009

- GIMÉNEZ YANGUAS, M.; PIÑAR SAMOS, J. (2013) Motril y el Azúcar. Paisaje, historia, patrimonio. Granada: Fundación El Legado Andalusí, 2013

- GómEZ DíAZ, D. (1991/92) Tendencias económicas y empresariales de la producción azucarera en la provincia de Almería, siglos XVI-XX. Paralelo 37, n. ${ }^{\circ}$ 14-15, 19911992, pp. 69-92

- MALPICA CUELLO, A. (1991) Arqueología y Azúcar, estudio de un conjunto preindustrial azucarero en el Reino de Granada: La Palma (Motril). En Actas del segundo Seminario Internacional: la caña de azúcar en el Mediterráneo. Motril: Ayuntamiento, Arte, Investigación y Publicaciones, D.L. 1991, pp. 123-210

- PIÑAR SAMOS, J. (1995) Azúcar y paisaje en la vega del Guadalfeo 1752-1930. En Paisajes del azúcar: Actas del Quinto Seminario Internacional sobre la caña de azúcar. Granada: Diputación Provincial, 1995, pp. 179-241
- SAGRA, R. (DE LA) (1845) Informe sobre el cultivo de la caña y la fabricación del azúcar en las costas de Andalucía presentado la empresa azucarera peninsular. Madrid: [s.n.], 1845 (imprenta del Colegio de Sordo-Mudos y Ciegos)

- SÁNCHEZ SÁNCHEZ, F. J. (2013) La Arquitectura del Azúcar en Andalucía Oriental. Granada: Universidad, 2013

- SANTIAGO RAMOS, A.; GUZMÁN VALDIVIA, A. (2007) Patrimonio Industrial. La Axarquía: CEDER-Axarquía, 2007

- RODRíguez MARÍN, F. J. (2011) Patrimonio y Ciudad. Patrimonio industrial azucarero en la Axarquía: entre el olvido y la puesta en valor. Isla de Arriarán, n. ${ }^{\circ} 37,2011$, pp. 7-44

- RUIZ GARcía, P. (2000) La Axarquía, tierra de azúcar. Granada: Asukaría Mediterránea, 2000 